\section{The critically ill patient with COVID- 19 and ARDS: Providing rational solutions to new and old challenges}

Keevan Singh ${ }^{1,2}$, Dale Ventour ${ }^{1,3}$, Sophia Cipriani ${ }^{2}$

${ }^{1}$ University of the West Indies. Anaesthesia \& Intensive Care Unit. St Augustine, Trinidad.

${ }^{2}$ San Fernando General Hospital. Anaesthesia \& Intensive Care Unit. San Fernando. Trinidad.

${ }^{3}$ Eric Williams Medical Sciences Complex. Anaesthesia \& Intensive Care Unit. Mt. Hope. Trinidad.

\section{Corresponding author:}

Dr Keevan Singh.

Anaesthesia \& Intensive Care Unit

University of the West Indies, St Augustine

Trinidad and Tobago

Email:keevansingh@gmail.com

DOI: $10.48107 / C M J .2020 .12 .005$

Copyright:

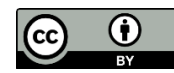

This is an open access article under the terms of the Creative Commons Attribution License which permits use, distribution and reproduction in any medium, provided the original work is properly cited.

\section{BACKGROUND}

The onset of COVID-19 has bought many aspects of critical care to the forefront both locally and internationally with infected patients presenting to Intensive Care Units (ICU) with an Acute Respiratory Distress (ARDS) type picture. Many of the challenges posed by COVID-19 are not new to Intensive Care Medicine, albeit unfamiliar to those outside the specialty. In the patient with ARDS, although established standards of care exist, there still remain unanswered questions on optimal ventilation settings, decisions to intubate and the use of adjunctive therapy. In this review we discuss some of the challenges of COVID-19 and its interaction with these foundational issues in critical care.

\section{DOES COVID-19 CAUSE ARDS?}

ARDS is a common ICU diagnosis and there have been significant advancements during the last decade in the care of patients that can be classified as such. However, ARDS is still associated with significant global mortality. ${ }^{1}$ Even though diagnostic criteria and treatment guidelines exist, ARDS treatment still requires a high level of critical care expertise and experience. ${ }^{2,3}$

At the onset, COVID-19 appeared to behave differently from the various viral and bacterial causes of ARDS. ${ }^{4}$

Hypoxemia was present in some patients with little signs of respiratory distress and lung fields lacked significant infiltrates. ${ }^{4,5}$ These patients also responded less well to common ARDS strategies like high Positive End Expiratory Pressure (PEEP) and prone ventilation with their lung compliance being relatively normal. Another subgroup of COVID-19 positive patients did in fact present very similar to usual ARDS phenotypes. These both groups of patients fit the standard Berlin criteria for ARDS.

Gattinoni et al., in his now classic paper, sought to classify these presentations into the $\mathrm{L}$ and $\mathrm{H}$ phenotypes with suggested treatment approaches. ${ }^{5}$ Hypoxemia in the $\mathrm{L}$ type occurred as a result of low V/Q ratios and $\mathrm{H}$ type as a result of increased right to left shunt and thus being more responsive to standard ARDS based therapies. This heterogeneity in presentation underscores the need for individualized care.

Subsequent data has shown that, as a group, most 
COVID-19 patients do have respiratory mechanics (low lung compliance) in keeping with ARDS from non COVID19 etiologies. ${ }^{6-8}$ This has led one group of authors to conclude that, "for most patients, COVID-19-associated ARDS is, in the end, ARDS". ${ }^{6}$ Nonetheless, oversimplification at this point may ignore the heterogeneity and the varied phenotypes of ARDS that have been previously established ${ }^{6,9}$

Hyper and hypo-inflammatory ARDS variants are well described with a higher mortality noted in hyperinflammatory subtypes. ${ }^{9}$ There is also a potential for different responses to fluids and PEEP levels based on these subtypes. ${ }^{6}$ Hence, present understanding of ARDS can accommodate these sometimes varied COVID-19 presentations. Additionally, beneficial treatment in ARDS shown from the various randomized controlled trials have been performed in patients with broad ARDS criteria. ${ }^{10-12}$ As COVID-19 patients do fulfill these criteria, it seems logical that COVID-19 patients should likewise benefit. Fundamental to the therapeutic approach in ARDS is the prevention of further ventilator induced lung injury. This general approach should be adapted and individualized for each COVID patient and is discussed later in this article.

\section{Considering the ARDS etiology in COVID-19}

The general grouping of similar patients as ARDS allows for many research and therapeutic advantages for the entire group. The downside to this is that specific conditions with therapeutic options may be missed. These so called ARDS "mimickers" can have potentially reversible lung conditions once the appropriate treatment is started. ${ }^{13-15}$ This contrasts with the current approach that focuses on waiting and preventing further lung injury. In the majority of ARDS mimickers the specific treatment required is corticosteroid use. ${ }^{14,15}$ Diagnosis can be challenging in these cases with CT scanning, bronchoalveolar lavage and even lung biopsy being necessary at times.

One of these known mimickers, Organizing Pneumonia (OP), has recently been suggested as a possible cause of ARDS in COVID-19 patients. ${ }^{16,17}$ Kory et al. using radiologic, pathologic and therapeutic response to steroids, argue that an OP is the likely cause of the atypical ARDS presentation ( $L$ type). ${ }^{17}$ Implications of this may be that even higher doses of steroids than currently recommended may be needed for treatment.
Whether COVID-19 proves to be an OP will only be confirmed with time. In the interim, the use of higher dose methylprednisolone has proven to be highly effective in select local cases. High dose methylprednisolone has also been used in several treatment protocols and shown to be effective in recent case series ${ }^{18-21}$

Suppression of the exaggerated immune response is another suggested mechanism for the efficacy of corticosteroid use in COVID-19. Cytokine storm, bradykinin storm and secondary hemophagocytic lymphohistiocytosis (HLH) have been suggested as potential consequences of COVID-19 infection. ${ }^{22-24}$ This dysregulated immune response can lead to pulmonary endothelial and alveolar epithelial damage that causes vascular leak and alveolar edema seen in ARDS. Additionally a COVID-19 induced coagulopathy and associated pulmonary vascular endothelial damage can lead to pulmonary microemboli which can further worsen oxygenation. ${ }^{25}$

Critical care physicians need to be vigilant for these signs of hyperinflammation such as increasing ferritin, cytopenias and fever. The $\mathrm{H}$ score used in HLH diagnosis has also been suggested for use. ${ }^{22}$ Other readily available clinical markers such as LDH levels and neutrophil to lymphocyte ratio (NLR) have also shown to have prognostic significance and should be assessed regularly. ${ }^{26,27}$ These markers can also be used to assess the effects of steroid use and possible dose escalation or de-escalation of therapy.

\section{When do you intubate the hypoxemic COVID 19 patient?}

Decisions regarding timing of intubation are amongst the most challenging to make and especially so in a COVID19 setting. Intubation is best seen as a package of care that includes sedation, close ICU monitoring, use of aerosol generating Personal Protective Equipment (PPE), appropriate ventilator management and specialized nursing and medical care. When these are in short supply, a liberal intubation strategy will surely increase morbidity and mortality while a too conservative strategy can lead to a worsening of lung injury and organ dysfunction making salvage less likely.

In his paper on COVID-19 phenotypes, Gattinoni et al. recommended early intubation and implementation of 
lung protective ventilation in L-type COVID ARDS to prevent progression to $\mathrm{H}$ type ARDS. ${ }^{5}$ The large tidal volumes and negative pleural pressure swings in the spontaneously breathing COVID-19 patient with respiratory distress was postulated to lead to patient spontaneous induced lung injury (P-SILI) ${ }^{5,28}$ Prompt intubation with the implementation of protective ventilation was suggested as the solution to P-SILI. However, this initial approach has been argued against by several authors. ${ }^{6}$ Clinical experience, both internationally and locally, has shown that patients with severe COVID19 pneumonia can be managed without intubation ${ }^{29}$

Determining which patients are at the greatest risk of PSILI can help in the overall determination of when to intubate. Knee jerk reactions based on hypoxemia and tachypnea can lead to unnecessary intubations and the morbidity and mortality associated with mechanical ventilation. Tachypnea with respiratory rates between 25$35 \mathrm{bpm}$ are a normal response to lung inflammation seen in COVID-19. ${ }^{30}$ Likewise, hypoxemia without other signs of distress should be considered in the context of oxygen delivery. Recent data has shown that targeting an oxygen saturation of $90 \%$ in critically ill patients requiring mechanical ventilation is in fact safe. ${ }^{31}$ Indeed, targeting oxygen saturations above $96 \%$ has even been shown to be harmful in the critically ill patient. ${ }^{32}$

In an excellent article which underscores physiologic principles, Tobin urged clinicians to focus on combining readily available clinical parameters to determine which patients are exhibiting increased work of breathing and hence may be at risk of P-SILI ${ }^{33,34}$ These parameters include palpation for tonic contraction of the sternocleidomastoid (not phasic), palpation at the thyroid cartilage for tracheal tug and observation of suprasternal recession. ${ }^{34}$ Additionally, failure to respond to an increasing amount of inspired oxygen indicates the existence of a significant shunt that may lead to an early need for mechanical ventilation. ${ }^{33,35}$ Applying these qualitative clinical signs and physiologic rationale may help the clinician readily identify patients who require early intubation. Ultimately, the decision remains based on an experienced Intensivist's clinical gestalt at the bedside, after considering the previously mentioned factors.

\section{Individualized Care of the Mechanically Ventilated Patient with COVID-19}

Given the differing lung mechanics seen in the L-type and $\mathrm{H}$-type presentations, Gattinoni et al. suggested a different approach to management for each ${ }^{5}$ It is important to recognize that patients can progress from type $L$ to type $H$, possibly due to P-SILI as well as progression of the disease. ${ }^{4,5}$ These varied presentations necessitate individualized care.

L-type patients would not seem to benefit from traditional high PEEP strategies as these patients' lung mechanics are generally preserved and this may lead to barotrauma, hemodynamic instability, overdistension, worsening lung injury and increasing pressor support. ${ }^{5}$ It was also initially suggested that these patients with relatively normal compliance may be ventilated with relatively higher tidal volumes if hypercapnic and with PEEP levels between 8$10 \mathrm{cmH}_{2} \mathrm{O}$. While this lower PEEP may be beneficial, this higher tidal volume strategy will not be lung protective. Numerous studies have demonstrated that even with low plateau pressures or relatively normal lungs, low tidal volume ventilation was associated with improved clinical outcomes. ${ }^{11,36}$ The same should be applied even for the relatively normal lung compliance (L-type) COVID-19 patient. Additionally, prone positioning may not benefit these patients due to their low recruitability ${ }^{5}$

H-type patients, reduced lung compliance, should be treated with a more conventional ARDS approach. This includes standard lung protective low tidal volume ventilation, relatively higher PEEP, as well as prone positioning and paralysis when needed. ${ }^{6}$ As with all ARDS patients plateau pressures should be kept at less than $30 \mathrm{cmH}_{2} \mathrm{O}$ and a driving pressure no greater than $14 \mathrm{cmH}_{2} \mathrm{O}^{2,37}$ While some clinicians advocate for higher PEEP in keeping with the ARDS Network PEEP- $-\mathrm{FiO}_{2}$ table, clinicians at the Jinyintan Hospital noted that this led to extremely high plateau pressures and high driving pressures or hypotension, with only modest improvement in oxygenation. ${ }^{38}$ This finding underscores a personalized approach to mechanical ventilation as all patients may not respond to a high PEEP approach.

Additionally, clinicians should consider that an improvement in oxygenation from higher PEEP levels can 
also be caused by decreased cardiac output and a redistribution of lung perfusion to a normally ventilated compartment. ${ }^{39,40}$ Often, the cost of high PEEP is hemodynamic compromise with an inevitable decrease in oxygen delivery, despite the improvement in oxygenation. Indeed, despite decades of research, it may seem that the best PEEP is in fact a compromise between oxygenation and hemodynamics.

It would seem beneficial to have an individualized approach to titration of PEEP by assessing recruitability and thereby avoiding overdistension of alveoli. Recently, a recruitability to inflation $(\mathrm{R} / \mathrm{I})$ ratio has been described. ${ }^{41}$ This is a practical bedside test whereby a higher PEEP is applied to estimate how much an increase in end expiratory lung volume is distributed between recruited lung and 'baby lung'. The ratio ranges from 0 to 2.0 with higher ratios indicating a higher likelihood of recruitment. Apart from titrating PEEP, it can be used for assessment intermittently during the treatment. In one study, patients assessed 4-6 days later had changed from poorly recruitable to highly recruitable ${ }^{42}$

Another useful strategy to determine lung recruitability and set PEEP include using driving pressure as a marker of lung compliance. ${ }^{37}$ Any changes to lung compliance based on tidal volume or PEEP settings can be determined by frequent measurement of driving pressure, which is relatively easy to determine on most modern ventilators. Assessing lung recruitability using CT scanning and lung ultrasound are also proposed methods to determine the amount of recruitable lung ${ }^{43,44}$ More consolidated/ground glass lung parenchyma or homogenous $B$ lines on ultrasound indicate potentially more recruitable lung and more PEEP can be used by the clinicians if desired. We would recommend a synergistic approach incorporating several of the above methods with frequent patient assessment as opposed to application of preset high PEEP levels by the clinician.

Proning has also been shown to accomplish alveolar recruitment and reduce Ventilator Induced Lung Injury (VILI). The PROSEVA trial found a significant reduction in 28 day and 90 day mortality in patients with severe ARDS who were proned. ${ }^{12}$ Interestingly, Pan et al. employed the use of the R/I ratio and found that patients who were not proned continued to have poor recruitability and those who were proned were associated with increased recruitability. ${ }^{38}$

Alternative ventilator modes, such as APRV (airway pressure release ventilation), are also excellent options as spontaneous breathing is preserved while still maintaining an open lung with a potentially lower risk of barotrauma. Zhou et al. have shown more ventilator free days and more successful extubation when APRV is used as the primary mode in ARDS. ${ }^{45}$ Local experience has shown success using this mode in patients with refractory hypoxemia. Due to the complexity involved, local ICUs should seek to develop expertise in this mode allowing it to be used as either a primary or secondary mode in patients with refractory hypoxemia.

\section{ANTI-INFLAMMATORY THERAPY IN COVID-19}

There was a common trend seen early during the COVID19 pandemic, with patients presenting with a hyperinflammatory syndrome with close similarities to secondary hemophagocytic lymphohistiocytosis (sHLH), a reactive hyperferritinemia hyper-cytokinemic immune syndrome. ${ }^{22}$ There was also reported success with the institution of corticosteroid therapy but the course and dose of therapy has varied between studies. ${ }^{20,21}$

There still remain unanswered questions regarding steroid use, although corticosteroid use is now advocated by the World Health Organization (WHO) consensus statement. ${ }^{46}$ A 7 to 10 day steroid course is now supported, but the inflammatory syndrome can relapse or continue after this period. ${ }^{46,47}$ The consensus statement presently supports dexamethasone as the steroid of choice although the use of methylprednisolone may be considered, as discussed previously ${ }^{46}$ Given the ongoing nature of the pandemic, clinicians should remain open minded to consider the pathophysiology of the disease and incorporate these new insights into patient management in a controlled manner.

There is also growing evidence supporting the use of the Il-6 inhibitor, Tocilizumab in COVID-19 cytokine storm. There are however reported risks and weaker evidence at this time to support its routine use, despite the success seen by $\mathrm{Xu}$ et al. ${ }^{48}$ Tocilizumab may also be associated with myocarditis and even disease aggravation in COVID19 cytokine storm patients ${ }^{49,50}$ Other anti-inflammatories currently in trials include the anti-Il 6, Siltuximab, Sarilumab and Anti-interferon beta/alpha inhibitors such 
as Interferon beta-1b and Emapulumab. ${ }^{23}$

\section{FUTURE TRENDS}

As the influenza season approaches, a new problem of co-infection lurks on the horizon. An analysis by Public Health England (PHE) of cases from January to April 2020 found that persons with both influenza and COVID-19 were more at risk of severe illness. ${ }^{51}$ These persons infected with both influenza and COVID-19 tended to be older and more than twice as likely to die as someone with COVID-19 alone. As we approach the flu season we need to be guided by areas in the world who have already experienced their winter, such as Australia. This may assist in determining the most effective influenza vaccination, as there is already extensive exposure to COVID-19 (approaching an estimated 36 million patients testing positive).$^{52}$

There is also a suggestion that the immunologic reaction to this virus is based primarily on chromosome 3 , leading to a potential genetic predisposition in certain individuals. ${ }^{53}$

We are potentially approaching a new entity with Influenza and COVID-19 co-infection. Steroids and other novel immunomodulatory therapies may continue to play a significant role in the treatment of these viral pneumonias in the near future.

For the forseeable future, the challenge of COVID-19 will continue. The last line of defense will inevitably remain our Intensive Care Units and the care patients receive via the specialist physicians and nurses working there.

Ethical Approval statement: not applicable Conflict of interest statement: None declared Informed Consent statement: Not applicable Funding statement: none

Authors Contribution: KS and DV conceptualised the article. KS, DV and SC wrote the article. All authors have reviewed and approved the final manuscript.

\section{REFERENCES}

1. Bellani G, Laffey JG, Pham T, Fan E, Brochard L, Esteban A, et al. Epidemiology, Patterns of Care, and Mortality for Patients With Acute Respiratory Distress

CMJ | Published online on December 12th, 2020
Syndrome in Intensive Care Units in 50 Countries. JAMA 2016;315:788-800. https://doi.org/10.1001/ jama.2016.0291.

2. Bein T, Grasso S, Moerer O, Quintel M, Guerin C, Deja $M$, et al. The standard of care of patients with ARDS: ventilatory settings and rescue therapies for refractory hypoxemia. Intensive Care Med 2016;42:699-711. https://doi.org/10.1007/s00134016-4325-4.

3. ARDS Definition Task Force, Ranieri VM, Rubenfeld GD, Thompson BT, Ferguson ND, Caldwell E, et al. Acute respiratory distress syndrome: the Berlin Definition. JAMA 2012;307:2526-33. https:// doi.org/10.1001/jama.2012.5669.

4. Gattinoni L, Chiumello D, Rossi S. COVID-19 pneumonia: ARDS or not? Crit Care 2020;24:154. https://doi.org/10.1186/s13054-020-02880-z.

5. Gattinoni L, Chiumello D, Caironi P, Busana M, Romitti F, Brazzi L, et al. COVID-19 pneumonia: different respiratory treatments for different phenotypes? Intensive Care Med 2020:1-4. https:// doi.org/10.1007/s00134-020-06033-2.

6. Fan E, Beitler JR, Brochard L, Calfee CS, Ferguson ND, Slutsky AS, et al. COVID-19-associated acute respiratory distress syndrome: is a different approach to management warranted? Lancet Respir Med 2020;8:816-21. https://doi.org/10.1016/S2213-2600 (20)30304-0.

7. Haudebourg A-F, Perier F, Tuffet $S$, de Prost N, Razazi K, Mekontso Dessap A, et al. Respiratory Mechanics of COVID-19- versus Non-COVID-19associated Acute Respiratory Distress Syndrome. Am J Respir Crit Care Med 2020;202:287-90. https:// doi.org/10.1164/rccm.202004-1226LE.

8. Grieco DL, Bongiovanni F, Chen L, Menga LS, Cutuli SL, Pintaudi G, et al. Respiratory physiology of COVID -19-induced respiratory failure compared to ARDS of other etiologies. Crit Care 2020;24. https:// doi.org/10.1186/s13054-020-03253-2.

9. Shankar-Hari M, Fan E, Ferguson ND. Acute respiratory distress syndrome (ARDS) phenotyping. Intensive Care Med 2019;45:516-9. https:// doi.org/10.1007/s00134-018-5480-6.

10. Papazian L, Forel J-M, Gacouin A, Penot-Ragon C, Perrin G, Loundou A, et al. Neuromuscular blockers in early acute respiratory distress syndrome. N Engl J Med 2010;363:1107-16. https://doi.org/10.1056/ 
NEJMoa1005372.

11. Ventilation with Lower Tidal Volumes as Compared with Traditional Tidal Volumes for Acute Lung Injury and the Acute Respiratory Distress Syndrome. N Engl J Med 2000;342:1301-8. https://doi.org/10.1056/ NEJM200005043421801.

12. Guérin $C$, Reignier J, Richard J-C, Beuret $P$, Gacouin $A$, Boulain $T$, et al. Prone Positioning in Severe Acute Respiratory Distress Syndrome. N Engl J Med 2013;368:2159-68. https://doi.org/10.1056/ NEJMoa1214103.

13. Schwarz MI, Albert RK. "Imitators" of the ARDS: implications for diagnosis and treatment. Chest 2004;125:1530-5. https://doi.org/10.1378/ chest.125.4.1530.

14. Gibelin A, Parrot A, Maitre B, Brun-Buisson C, Mekontso Dessap A, Fartoukh M, et al. Acute respiratory distress syndrome mimickers lacking common risk factors of the Berlin definition. Intensive Care Med 2016;42:164-72. https://doi.org/10.1007/ s00134-015-4064-y.

15. Guérin C, Thompson T, Brower R. The ten diseases that look like ARDS. Intensive Care Med 2015;41:1099-102. https://doi.org/10.1007/s00134014-3608-x.

16. Copin M-C, Parmentier E, Duburcq T, Poissy J, Mathieu D. Time to consider histologic pattern of lung injury to treat critically ill patients with COVID-19 infection. Intensive Care Med 2020:1-3. https:// doi.org/10.1007/s00134-020-06057-8.

17. Kory P, Kanne JP. SARS-CoV-2 organising pneumonia: 'Has there been a widespread failure to identify and treat this prevalent condition in COVID19?' BMJ Open Respir Res 2020;7. https:// doi.org/10.1136/bmjresp-2020-000724.

18. COVID Care for Clinicians - Eastern Virginia Medical School (EVMS), Norfolk, Hampton Roads n.d. https:// www.evms.edu/covid-19/covid_care_for_clinicians/ (accessed September 29, 2020).

19. So C, Ro S, Murakami M, Imai R, Jinta T. High-dose, short-term corticosteroids for ARDS caused by COVID -19: a case series. Respirol Case Rep 2020;8:e00596. https://doi.org/10.1002/rcr2.596.

20. Kolilekas L, Loverdos K, Giannakaki S, Vlassi L, Levounets $A$, Zervas $E$, et al. Can steroids reverse the severe COVID-19 induced "cytokine storm"? J Med Virol 2020;92:2866-9. https://doi.org/10.1002/ jmv.26165.

21. Liu J, Zheng $X$, Huang $Y$, Shan H, Huang J. Successful use of methylprednisolone for treating severe COVID-19. J Allergy Clin Immunol 2020;146:325-7. https://doi.org/10.1016/ j.jaci.2020.05.021.

22. Mehta P, McAuley DF, Brown M, Sanchez E, Tattersall RS, Manson JJ, et al. COVID-19: consider cytokine storm syndromes and immunosuppression. Lancet Lond Engl 2020;395:1033-4. https:// doi.org/10.1016/S0140-6736(20)30628-0.

23. Castelli V, Cimini A, Ferri C. Cytokine Storm in COVID -19: "When You Come Out of the Storm, You Won't Be the Same Person Who Walked in." Front Immunol 2020;11:2132. https://doi.org/10.3389/ fimmu.2020.02132.

24. Roche JA, Roche R. A hypothesized role for dysregulated bradykinin signaling in COVID-19 respiratory complications. FASEB J 2020. https:// doi.org/10.1096/fj.202000967.

25. Iba T, Connors JM, Levy JH. The coagulopathy, endotheliopathy, and vasculitis of COVID-19. Inflamm Res 2020:1-9. https://doi.org/10.1007/s00011-02001401-6.

26. Henry BM, Aggarwal G, Wong J, Benoit S, Vikse J, Plebani $M$, et al. Lactate dehydrogenase levels predict coronavirus disease 2019 (COVID-19) severity and mortality: A pooled analysis. Am J Emerg Med 2020;38:1722-6. https://doi.org/10.1016/ j.ajem.2020.05.073.

27. Yang A-P, Liu J, Tao W, Li H. The diagnostic and predictive role of NLR, d-NLR and PLR in COVID-19 patients. Int Immunopharmacol 2020;84:106504. https://doi.org/10.1016/j.intimp.2020.106504.

28. Brochard L, Slutsky A, Pesenti A. Mechanical Ventilation to Minimize Progression of Lung Injury in Acute Respiratory Failure. Am J Respir Crit Care Med 2017;195:438-42. https://doi.org/10.1164/ rccm.201605-1081CP.

29. Vianello A, Arcaro G, Molena B, Turato C, Sukthi A, Guarnieri $G$, et al. High-flow nasal cannula oxygen therapy to treat patients with hypoxemic acute respiratory failure consequent to SARS-CoV-2 infection. Thorax 2020. https://doi.org/10.1136/ thoraxjnl-2020-214993.

30. Tobin MJ. Basing Respiratory Management of COVID19 on Physiological Principles. Am J Respir Crit Care 
Med 2020;201:1319-20. https://doi.org/10.1164/ rccm.202004-1076ED.

31. ICU-ROX Investigators and the Australian and New Zealand Intensive Care Society Clinical Trials Group, Mackle D, Bellomo R, Bailey M, Beasley R, Deane A, et al. Conservative Oxygen Therapy during Mechanical Ventilation in the ICU. N Engl J Med 2020;382:989-98. https://doi.org/10.1056/ NEJMoa1903297.

32. Chu DK, Kim LH-Y, Young PJ, Zamiri N, Almenawer $\mathrm{SA}$, Jaeschke $\mathrm{R}$, et al. Mortality and morbidity in acutely ill adults treated with liberal versus conservative oxygen therapy (IOTA): a systematic review and meta-analysis. Lancet Lond Engl 2018;391:1693-705. https://doi.org/10.1016/S01406736(18)30479-3.

33. Tobin MJ. Basing Respiratory Management of COVID19 on Physiological Principles. Am J Respir Crit Care Med 2020;201:1319-20. https://doi.org/10.1164/ rccm.202004-1076ED.

34. Tobin MJ. Why Physiology Is Critical to the Practice of Medicine: A 40-year Personal Perspective. Clin Chest Med 2019;40:243-57. https://doi.org/10.1016/ j.ccm.2019.02.012.

35. Gattinoni L, Carlesso E, Brazzi L, Cressoni M, Rosseau $S$, Kluge $S$, et al. Friday night ventilation: a safety starting tool kit for mechanically ventilated patients. Minerva Anestesiol 2014;80:1046-57.

36. Walkey AJ, Goligher EC, Del Sorbo L, Hodgson CL, Adhikari NKJ, Wunsch $\mathrm{H}$, et al. Low Tidal Volume versus Non-Volume-Limited Strategies for Patients with Acute Respiratory Distress Syndrome. A Systematic Review and Meta-Analysis. Ann Am Thorac Soc 2017;14:S271-9. https:// doi.org/10.1513/AnnalsATS.201704-3370T.

37. Amato MBP, Meade MO, Slutsky AS, Brochard L, Costa ELV, Schoenfeld DA, et al. Driving pressure and survival in the acute respiratory distress syndrome. N Engl J Med 2015;372:747-55. https:// doi.org/10.1056/NEJMsa1410639.

38. Pan C, Chen L, Lu C, Zhang W, Xia J-A, Sklar MC, et al. Lung Recruitability in COVID-19-associated Acute Respiratory Distress Syndrome: A Single-Center Observational Study. Am J Respir Crit Care Med 2020;201:1294-7. https://doi.org/10.1164/ rccm.202003-0527LE.

39. Grieco DL, Bongiovanni F, Chen L, Menga LS, Cutuli
SL, Pintaudi G, et al. Respiratory physiology of COVID -19-induced respiratory failure compared to ARDS of other etiologies. Crit Care 2020;24. https:// doi.org/10.1186/s13054-020-03253-2.

40. Mauri T, Spinelli E, Scotti E, Colussi G, Basile MC, Crotti S, et al. Potential for Lung Recruitment and Ventilation-Perfusion Mismatch in Patients With the Acute Respiratory Distress Syndrome From Coronavirus Disease 2019*. Crit Care Med 2020;48:1129-34. https://doi.org/10.1097/ CCM. 0000000000004386.

41. Chen L, Del Sorbo L, Grieco DL, Junhasavasdikul D, Rittayamai N, Soliman I, et al. Potential for Lung Recruitment Estimated by the Recruitment-toInflation Ratio in Acute Respiratory Distress Syndrome. A Clinical Trial. Am J Respir Crit Care Med 2020;201:178-87. https://doi.org/10.1164/ rccm.201902-03340C.

42. Beloncle FM, Pavlovsky B, Desprez C, Fage N, Olivier $P-Y$, Asfar $P$, et al. Recruitability and effect of PEEP in SARS-Cov-2-associated acute respiratory distress syndrome. Ann Intensive Care 2020;10:55. https:// doi.org/10.1186/s13613-020-00675-7.

43. Sahetya SK, Goligher EC, Brower RG. Fifty Years of Research in ARDS.Setting Positive End-Expiratory Pressure in Acute Respiratory Distress Syndrome. Am J Respir Crit Care Med 2017;195:1429-38. https:// doi.org/10.1164/rccm.201610-2035CI.

44. Gattinoni L, Collino F, Maiolo G, Rapetti F, Romitti F, Tonetti $\mathrm{T}$, et al. Positive end-expiratory pressure: how to set it at the individual level. Ann Transl Med 2017;5. https://doi.org/10.21037/atm.2017.06.64.

45. Zhou $Y$, Jin X, Lv Y, Wang P, Yang Y, Liang G, et al. Early application of airway pressure release ventilation may reduce the duration of mechanical ventilation in acute respiratory distress syndrome. Intensive Care Med 2017;43:1648-59. https:// doi.org/10.1007/s00134-017-4912-z.

46. WHO. Corticosteroids for COVID-19 2020. https:// www.who.int/publications-detail-redirect/WHO-2019nCoV-Corticosteroids-2020.1 (accessed October 6, 2020).

47. WHO Rapid Evidence Appraisal for COVID-19 Therapies (REACT) Working Group, Sterne JAC, Murthy S, Diaz JV, Slutsky AS, Villar J, et al. Association Between Administration of Systemic Corticosteroids and Mortality Among Critically III 
Patients With COVID-19: A Meta-analysis. JAMA 2020. https://doi.org/10.1001/jama.2020.17023.

48. Xu X, Han M, Li T, Sun W, Wang D, Fu B, et al. Effective treatment of severe COVID-19 patients with tocilizumab. Proc Natl Acad Sci U S A 2020;117:10970 -5. https://doi.org/10.1073/pnas.2005615117.

49. Radbel J, Narayanan N, Bhatt PJ. Use of Tocilizumab for COVID-19-Induced Cytokine Release Syndrome: A Cautionary Case Report. Chest 2020;158:e15-9. https://doi.org/10.1016/j.chest.2020.04.024.

50. Luo P, Liu Y, Qiu L, Liu X, Liu D, Li J. Tocilizumab treatment in COVID-19: A single center experience. J Med Virol 2020;92:814-8. https://doi.org/10.1002/ jmv.25801.

51. Iacobucci G. Covid-19: Risk of death more than doubled in people who also had flu, English data show. BMJ 2020;370. https://doi.org/10.1136/ bmj.m3720.

52. Coronavirus Update (Live): Pandemic - Worldometer 2020. https://www.worldometers.info/coronavirus/ (accessed October 7, 2020).

53. Zeberg $\mathrm{H}$, Pääbo $\mathrm{S}$. The major genetic risk factor for severe COVID-19 is inherited from Neanderthals. Nature 2020. https://doi.org/10.1038/s41586-0202818-3. 